\title{
Editorial
}

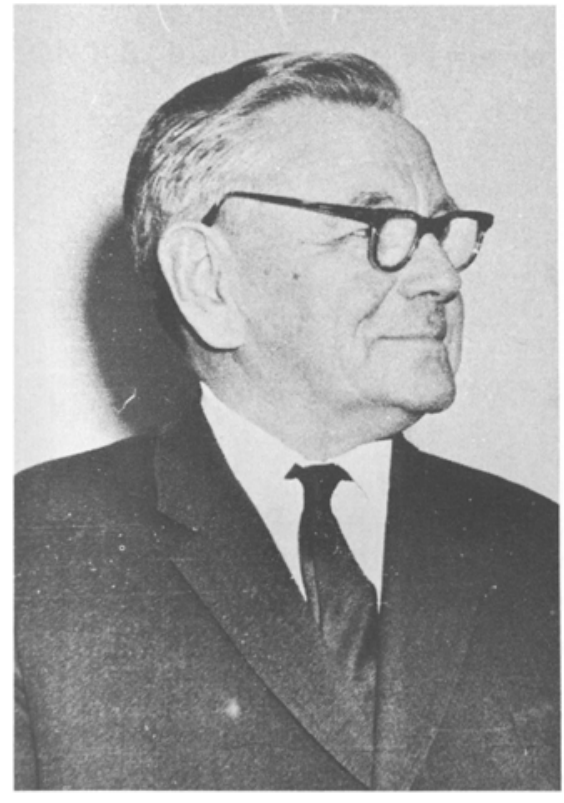

\section{In Memoriam Dr. K. V. Chmutov}

We regret to announce the sudden death of Dr. Konstantin Vasil'evich Chmutov, Professor of Physical Chemistry and the Chairman of the AllUnion Scientific Council on Chromatography of the Academy of Sciences of the U.S.S.R., on May 29, 1979. He was 77 years old.

Dr. Chmutov graduated from the Chemical Engineering Faculty of Moscow Technical University. While being in his third year as a student, he published in 1925 his first paper describing the investigations he carried out in the laboratory of the famous Russian scientist N. Shilov. These investigations concerned the interaction of ions in solution with charcoal. Based on this research Dr. Chmutov proposed a hypothesis about the existence of three types of surfaces of charcoal. The development of this idea later lead to organic ion exchangers and to ion-exchange chromatography.

In the following years Dr. Chmutov carried out detailed investigations on the adsorption of gases and vapors on charcoal which were summarized in a monograph written together with Dr. M. Dubinin. His further research on the kinetics and dynamics of sorption processes were summarized in 1940 in his thesis for the Doctor of Chemical Sciences degree entitled the Sorption Phenomena in Capillary Systems.
In 1950, Dr. Chmutov organized the Laboratory for Chromatography in the Institute of Physical Chemistry of the Academy of Science of the U.S.S.R. Together with his coworkers and students he carried out systematic investigations of the various processes and phenomena related to chromatographic separation in solution. His most important achievements concerned the selectivity of ion-exchange and molecular chromatography, the kinetics of chromatographic equilibria, and the dynamics of the separation process in columns including columns with larger diameter. Among others he also developed new versions for semiindustrial and industrial processes of ion-exchange chromatography of metal ions and for the purification of solutions.

Dr. Chmutov was the author and coauthor of more than 400 papers and six books including popular texts on chromatography. He was a brilliant experimentator developing simple laboratory apparatus which almost any chemist can put together himself.

Dr. Chmutov was the Chairman of the All-Union Council on Chromatography of the Academy of Science. In this capacity, he coordinated research on chromatography in various laboratories, organized a number of scientific symposia and meetings, and promoted the cooperation between scientists from the U.S.S.R. and other countries. He also served as the deputy director of the Academy's Institute of Physical Chemistry and was on the Editorial Board of the Soviet Journal of Physical Chemistry and the Journal of Chromatography.

Dr. Chmutov was very modest, had an excellent mind, golden hands and a clear feeling about the importance of the practical realization of theoretical ideas. He liked very much music, literature, art and particularly poetry: many times, he surprised his friends and colleagues with small poems illustrated with friendly cartoons. His death created an irreplaceable void in Soviet science.

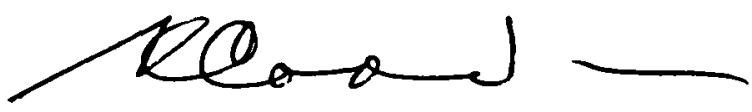

K. I. Sakodynskii 